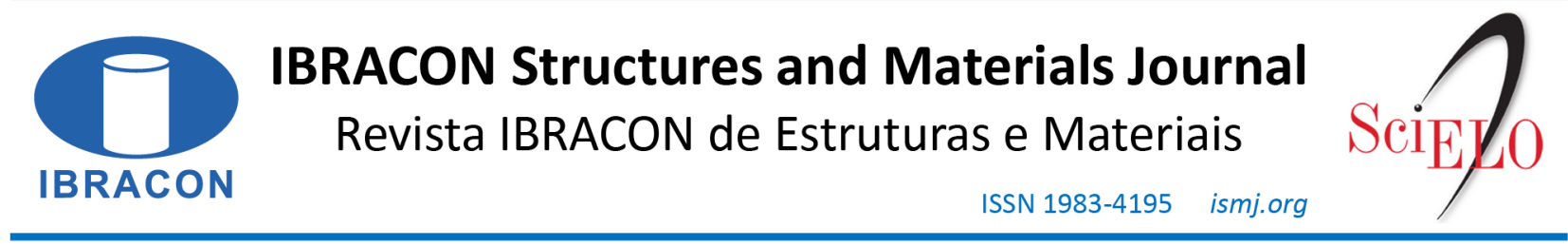

ORIGINAL ARTICLE

\title{
Towards improving the seismic hazard map and the response spectrum for the state of RN/Brazil
}

\section{Em busca da melhoria do mapa de perigo sísmico e do espectro de resposta do estado do RN/Brasil}

\author{
Petrus Gorgônio Bulhões da Nóbrega ${ }^{a}$ (D) \\ Bruno Rammon Silva Souza ${ }^{\mathrm{a}}$ (D) \\ Selma Hissae Shimura da Nóbrega ${ }^{a}$
}

${ }^{a}$ Universidade Federal do Rio Grande do Norte - UFRN, Centro de Tecnologia, Campus Universitário Lagoa Nova, Natal, RN, Brasil

Received 18 July 2020

Accepted 28 October 2020

\begin{abstract}
Although Brazilian seismic activity is defined as low to moderate, it is known that intraplate earthquakes can also be associated to high intensities. In Brazil, the state of Rio Grande do Norte (RN) is one of the most seismically active areas, but there is no specific study to evaluate the seismic hazard in this region. This paper presents analyses towards improving the seismic hazard map, the peak ground acceleration value and the response spectrum of RN. The methodology is based on Probabilistic Seismic Hazard Analysis, comparing the results to the design criteria defined in the Brazilian code NBR 15421:2006 (Design of seismic resistant structures - Procedure). The analyses show that, in general, the code sets conservative values for the peak ground acceleration and for the design response spectrum; however, related to this last one, the shape is quite different.
\end{abstract}

Keywords: seismic design, seismic hazard, response spectra, PSHA.

Resumo: Embora a atividade sísmica no Brasil seja definida como baixa a moderada, sabe-se que os terremotos intraplaca também podem produzir grandes intensidades. No Brasil, o estado do Rio Grande do Norte (RN) é uma das áreas sísmicas mais ativas, em relação ao qual inexiste qualquer estudo de avaliação do perigo sísmico. Este artigo apresenta análises em busca da melhoria do mapa de perigo sísmico, do valor da aceleração de pico, e do espectro de resposta do RN. A metodologia é baseada na Análise Probabilística de Perigo Sísmico, comparando os resultados com os critérios de projeto estabelecidos na norma Brasileira NBR 15421:2006 (Projeto de estruturas resistentes a sismo - Procedimento). As análises comprovam, em geral, que a norma define valores conservadores para a aceleração de pico e para o espectro de resposta de projeto, em relação ao qual o formato é muito diferente.

Palavras-chave: projeto sísmico, perigo sísmico, espectro de resposta, PSHA.

How to cite: P. G. B. Nóbrega, B. R. S. Souza, and S. H. S. Nóbrega, "Towards improving the seismic hazard map and the response spectrum for the state of RN/Brazil," IBRACON Struct. Mater. J., vol. 14, no. 3, e14302, 2021, https://doi.org/10.1590/S1983-41952021000300002

\section{INTRODUCTION}

The expression "hazard", in common words, means the situation or agent that can cause harm, damage or an adverse effect to humans, properties, or the environment. The hazard is real, if it occurs here and now, or potential, when it may happen in short, medium or long term, depending on the nature of its causes. In this context, the seismic hazard analysis, which is associated to the evaluation of the potential earthquake consequences, is important and proposed as the main theme of this paper, focusing the Rio Grande do Norte (RN), a state of the Brazilian Northeast region.

However, is there a real seismic hazard in Brazil, a country often considered free of earthquakes? Indeed, its geology and geographic position, in the middle of an extensive tectonic plate, contributes to a greater seismic stability than that

Corresponding author: Petrus Gorgônio Bulhões da Nóbrega. E-mail: petrus@ufrn.edu.br

Financial support: None.

Conflict of interest: Nothing to declare. 
presented by nearby countries as Chile, Peru, Ecuador and Colombia, which are along the South America plate borders. As stated by Talwani [1], the plate borders are the genesis location of more than $95 \%$ of the global seismic energy release and about $5 \%$ are developed intraplate.

It is obvious the earthquakes do occur in Brazil, and there are many historical and experimental data registered (Berrocal et al. [2], Bianchi et al. [3]). Lopes and Nunes [4] pointed out that in Brazil there is an average occurrence of less than two earthquakes greater than M4 per year ( $M$ means magnitude and the number is the numerical value correlated), one earthquake greater than M5 every six years (Assumpção et al. [5] indicates that events with M5 or above occur over four-year period, a slightly shorter term), and one M6 earthquake every forty-five years. Assumpção [6] complements this statistic indicating that M7 earthquakes are extremely rare, perhaps one every five hundred years, and M8 are "practically impossible".

Although Brazilian seismic activity is defined as low to moderate (Borges et al. [7], Talwani [1]), it is known that intraplate earthquakes can also be associated to high intensities (Talwani [8], Agurto-Detzel et al. [9]), especially if they are not deep, which is a general feature in Brazil, particularly in RN. Besides this first characteristic, a low attenuation in intraplate settings, such occurs in Brazil (Borges et al. [7]), makes greater intensities possible. The neotectonic activity in Brazilian Platform were described by Saadi [10] and Saadi et al. [11], and the possible correlations with geological and geophysical properties were detailed by Assumpção et al. [5] and Agurto-Detzel et al. [9].

According to Assumpção [6], one of the great difficulties in dealing with rare events is that the little known about the past does not ensure a set pattern in the future. For Seismic Engineering, the past is only a reference and the future is a probability, being the seismic hazard analysis the most appropriate way to deal with rare events and their possible consequences. At this point, it is important to carefully observe the two warnings made by Hough [12, pp. 304]: "Quantifying probabilistic seismic hazard remains a vexing problem in intraplate regions throughout the world" and "in intraplate regions, estimation of long-term earthquake rates is far more challenging".

After a hazard analysis, a seismic risk evaluation may be performed. Although the terms "hazard" and "risk" are often used interchangeably in usual sense, they are distinct terms used to the risk assessment. If the hazard is something that can cause harm, the risk is the chance or probability, high or low, that a person will be harmed or experience an adverse health effect if exposed to a hazard. This concept of risk may also be applied to property or equipment losses, or harmful effects on the environment (Pitilakis et al. [13], FEMA P-58-1 [14]). Obviously, there is no risk if there is no exposure to the hazard.

The exposure can be associated (or not) to another definition: the vulnerability, which can be generally described as the potential for loss. In fact, the vulnerability may cover the exposure (population and value exposed) and the various susceptibilities (physical, social, environmental, economic, among others). From this discussion, the following qualitative expression of the problem results:

Risk $=$ Hazard $\mathrm{x}$ Vulnerability $\mathrm{x}$ (Exposure)

Seismic vulnerability of a structure can be described as its susceptibility to damage by ground shaking of a given intensity, and the aim of a vulnerability assessment, due to an earthquake scenario, is to obtain the probability of a certain level of damage related to a given building type. It depends on the building typology, structural system, age, contents and use, plane and elevation regularity, design and detailing of the structural elements, materials employed, construction practices and ground conditions. A state-of-the-art review of the seismic vulnerability assessment methodologies was done by Kassem et al. [15].

A comparison between two real examples illustrates the vulnerability influence, although they do not reflect the Brazilian seismic hazard reality. On 12 January 2010, a 7.0 $\mathrm{M}_{\mathrm{W}}$ earthquake hits Haiti $\left(\mathrm{M}_{\mathrm{W}}\right.$ is the moment magnitude scale based on the seismic moment, a measure of the work done by the earthquake, considered the most reliable magnitude scale for ranking earthquakes because it is more directly related to the energy of an earthquake than the other scales). This country, unprepared for this type of phenomenon, registered the chaos and more than 200,000 deaths $(7 \%$ of the capital's population and $2.2 \%$ of the country's population). A few days later, on 27 February 2010 , a much larger earthquake occurred in Chile with a $8.8 \mathrm{M}_{\mathrm{W}}$ (which means, approximately, an earthquake 80 times greater with 800 times more energy released), resulting in 521 deaths, a corresponding number to $1 / 380$ of the total victims in Haiti.

Paultre et al. [16] noted that Haitian tragedy happened because the earthquake occurred in a heavily populated region of a very poor country with substandard building practices, in a city that had not, in any way, been prepared for such an eventuality. The mitigation and preparedness efforts were minimal, and the earthquake threat was not accounted for in construction, land-use planning, or emergency procedures. The authors estimated that approximately $90 \%$ of 
houses and buildings are built without the intervention of an architect or engineer, and a large portion of them are found in slums constructed on the mountainside terrain of Port-au-Prince and Pétionville cities.

If it is not possible to reduce the seismic hazard (a natural and uncontrollable characteristic), the alternative is to minimize the vulnerability in order to have an acceptable risk, with an economic and a social admissible cost. This is an aspect that must be considered by skeptics who neglect the seismic risk in Brazil. Although, in fact, the seismic hazard is not critical, compared to other countries, the people exposure and the buildings vulnerability of the large urban centers, especially the slums, tend to maximize the risk in case of a seismic event.

This paper focus on one variable of the Risk expression: Hazard. It presents an overview about the probabilistic seismic hazard analysis and the results of several analyses carried out for the state of RN, one of the most seismically active areas located in Brazil. The obtained results, expressed as exceedance probabilities of the horizontal peak ground acceleration values and acceleration response spectra, will be compared to the design parameters defined by NBR 15421 (ABNT [17]), the Brazilian code for the design of seismic resistant civil structures. The conclusions may serve as subsidies data for the NBR 15421 code discussion, which might be under revision process in the future.

\section{BRIEF DESCRIPTION OF THE SEISMIC CONTEXT IN RN STATE}

Figure 1 illustrates the most recent earthquake distribution maps for Brazil. Figure 1a refers to the general seismic catalog (1720 to 2019), where only earthquakes greater than M2.5 are plotted, also including historical events, not registered by instruments but indirectly inferred from reports and news (Berrocal et al. [2]). Figure $1 \mathrm{~b}$ refers to the uniform catalog (1939 to 2019), where the earthquakes greater than M3.5 are shown. This catalog is filtered according to the event's detectability, that is, only the most recent earthquakes with an equal chance of being detected anywhere in Brazil are plotted, and the different colors represent the major tectonic provinces of the South American stable continental region.
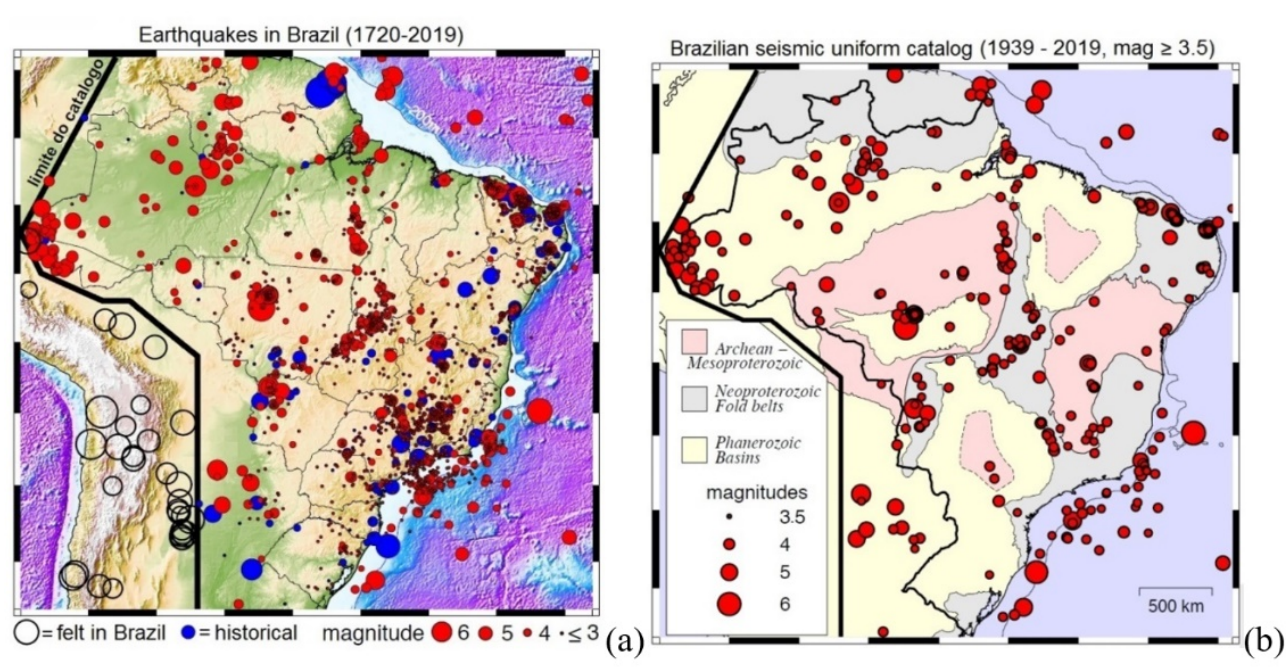

Figure 1. Brazilian seismic and uniform catalogs maps (adapted from M. S. Assumpção 2020, personal communication, 8 July).

It can be seen in Figure 1 that some areas present no relevant seismic activity and others are quite active. The earthquakes in the North region have greater magnitude but associated to few events. Probably this is due to underestimation generated by the low distribution of the Brazilian seismographic network, mainly in the North region, where the stations are about $500 \mathrm{~km}$ away from each other (Bianchi et al. [9]).

The state of RN, the focus of this study, is one of the most important seismic areas in Brazil (Ferreira et al. [18]). From the database, two events in the $1980 \mathrm{~s}$ with magnitude $\geq 5.0 \mathrm{~m}_{R}$ should be highlighted $\left(\mathrm{m}_{\mathrm{R}}\right.$ is the regional magnitude scale, formulated for the attenuation conditions of the seismic waves in the Brazilian lithosphere) and several others with magnitude greater than $4.0 \mathrm{~m}_{\mathrm{R}}$. RN represents $0.6 \%$ of the country's total area, but is approximately associated to $15 \%$ of the earthquakes. This aspect makes it one of Brazilian states with the highest seismic activity (the neighboring state Ceará, CE, presents about $17 \%$ of earthquakes with three times the area). 
Figure 2 shows the earthquakes distribution in $\mathrm{RN}$ and the area highlighted in blue refers to its capital, the city of Natal. The scale of the map does not allow a clear visualization of the strong seismic activity because almost 300 events are plotted in a small area causing overlapping points. In addition, there are hundreds of earthquakes less than M2 that have not been considered in this map. A review about the seismicity in $\mathrm{RN}$ and a description about the active faults with many geophysical details can be found in Ferreira et al. [18], Bezerra et al. [19] and Reis et al. [20].

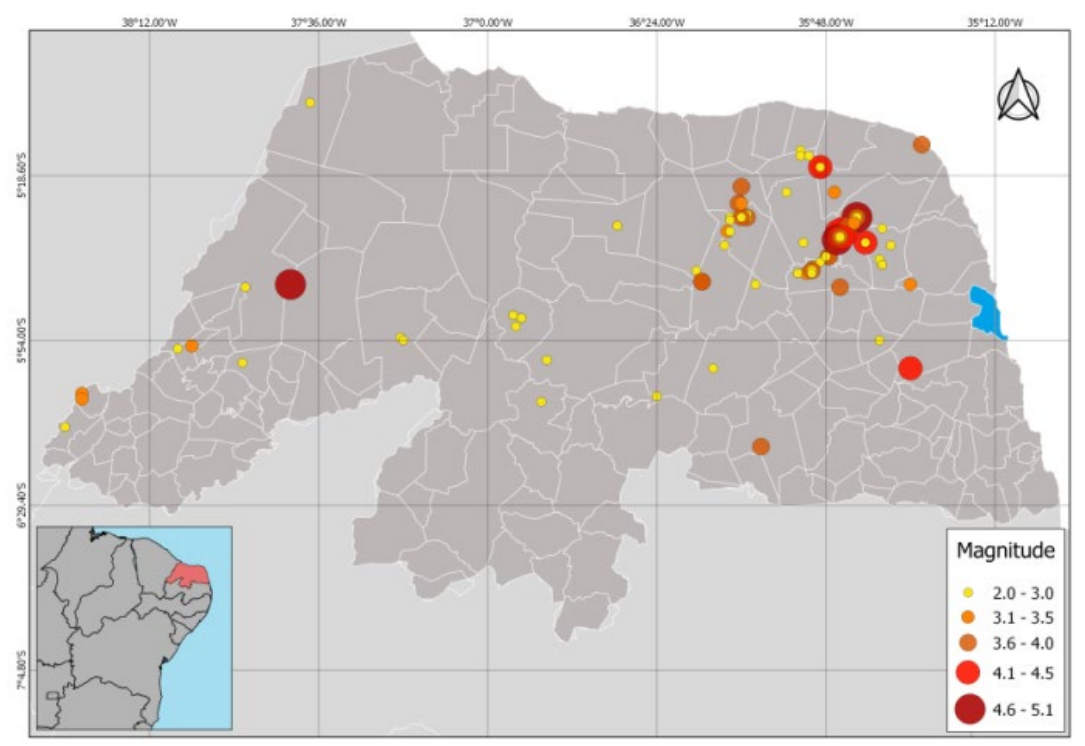

Figure 2. Seismic activity in $\mathrm{RN}$ (magnitude $\geq 2.0$ ).

The most important seismic source is the "Samambaia fault" (Figure 3), which forms a main alignment about 27 $\mathrm{km}$ long crossing the areas of the cities João Câmara (1) and Poço Branco (2), with ramifications to other cities. The depth of the seismic events is extremely low, ranging from $1 \mathrm{~km}$ to $9 \mathrm{~km}$ (Bezerra et al. [21]). Next to this fault, there is the "Poço Branco fault", which also contributes to the occurrence of earthquakes in the region.

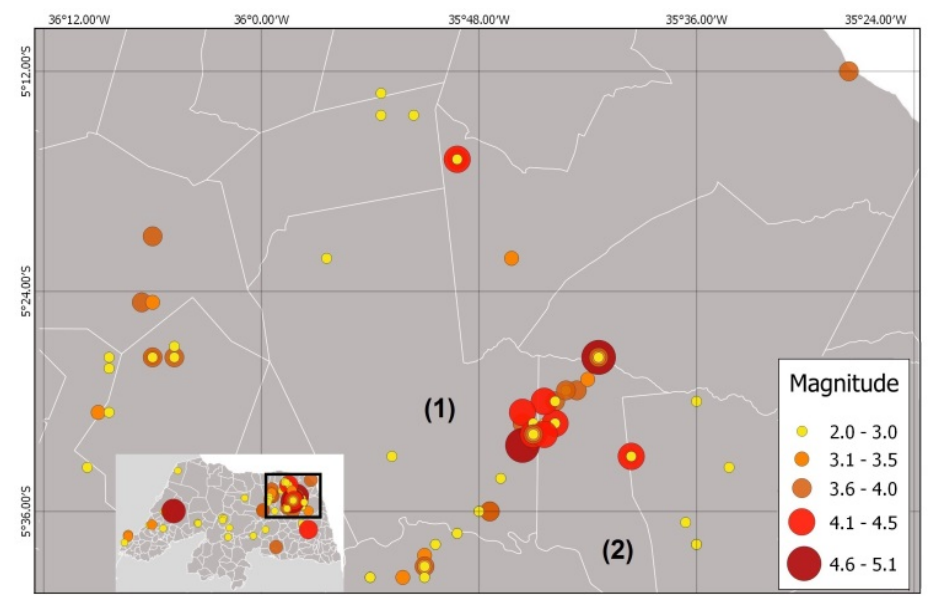

Figure 3. Seismic activity around "Samambaia fault".

\section{THE PSHA AND THE ACCELERATION MAP OF THE NBR 15421 CODE}

Seismic hazard can be represented in several ways, but this is usually done based on the distribution of acceleration (or velocity or displacement) of the ground surface. This happens because the destructive effects of an earthquake are 
related to the ground motion induced by the seismic waves. The seismic hazard analysis can be deterministic (DSHA, "Deterministic Seismic Hazard Analysis") or probabilistic (PSHA, "Probabilistic Seismic Hazard Analysis"), the latter being the most used methodology. A detailed review on PSHA is given by Reiter [22], McGuire [23] and Baker [24].

The PSHA process, as expressed by McGuire [23], incorporates several uncertainties in the probabilities calculation of the event occurrence, classified as "epistemic or knowledge uncertainties" (for example, seismic sources definition, election of the ground motion prediction equations, and maximum magnitude) and as "aleatory or random uncertainties" (for example, earthquake depth and variability of ground properties). Baker [24] states that if on one side the incorporation of uncertainties adds some complexity to the procedure, on the other side the resulting calculations are more defensible for use in engineering decision-making for reducing risks.

Recently, some researchers have studied the seismic hazard for some specific areas of Brazil performing PSHA: Almeida et al. [25] analyzed an area of the Southeast region, site of a nuclear power plant, and Borges et al. [7] studied the continental margin of Southeastern region. Besides them, Santos et al. [26] studied the seismic hazard for the Brazilian Northeastern region.

The technical resource that best guides the structural engineer is the seismic hazard map, which will show the ground movement levels in a given area for a certain occurrence probability, or for its exceedance, which means the probability of this value being exceeded.

The most common in maps is to present the maximum acceleration, or "Peak Ground Acceleration" (PGA), related to a probability of occurrence/exceedance during an exposure time, which implies (by statistical concept) in a "mean return period". Several different seismic hazard maps, indicated in sequence, can be found in technical literature or in international codes. Earthquakes with these characteristics are consistent with the ground-shaking levels: (a) likely, (b) possible, and (c) rare (Petersen et al. [27]), and it is easy to realize that they are in an increasing magnitude:

a) PGA with $50 \%$ probability of exceedance in 50 years, which corresponds to a mean return period of 72 years $(e . g$. ASCE [28]);

b) PGA with $10 \%$ probability of exceedance in 50 years, which corresponds to a mean return period of 475 years (e.g. CEN [29]);

c) PGA with $2 \%$ probability of exceedance in 50 years, which corresponds to a mean return period of 2475 years (e.g. ASCE [30]).

In addition to these traditional alternatives, there are other standards such as the seismic action with $10 \%$ probability of exceedance in 10 years, which corresponds to a mean return period of 95 years (e.g. CEN [29]); or the action with $20 \%$ probability of exceedance in 10 years, which corresponds to a mean return period of 45 years (e.g. ASCE [28]).

The NBR 15421 - Design of seismic resistant structures - Procedure (ABNT [17]) is the Brazilian code that sets methods, parameters and requirements to the consideration of seismic effects in civil building design. Among all these information, there are two fundamental criteria: (1) the characteristic horizontal seismic acceleration map (Figure 4a), which is exactly a PGA map with $10 \%$ probability of exceedance in 50 years, which corresponds to a mean return period of 475 years; and (2) the design response spectrum (Figure $4 b$ ).

For example, for a structure built in RN (Zone 1), the characteristic horizontal acceleration is $0.05 \mathrm{~g}(5 \% \mathrm{~g})$, considering rock soil type (according to NBR 15421, Class "B", the standard characteristic for this map). Based on the real soil and on the zone type (site) of the building, the design response spectrum is established, adopting a damping ratio of $5 \%$.

It has been 14 years since NBR 15421 was published and it should be under review process in the future. A detailed discussion of the acceleration map, its origin, criticisms and some new proposals can be found in Nóbrega et al. [31]. Santos and Lima [32] conclude that seismological studies in Brazil should be developed, evaluating the NBR 15421 code and pointing out the necessary modifications. 


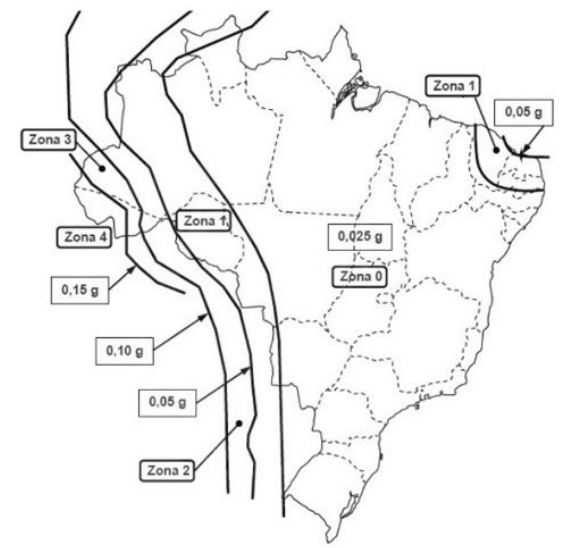

(a)

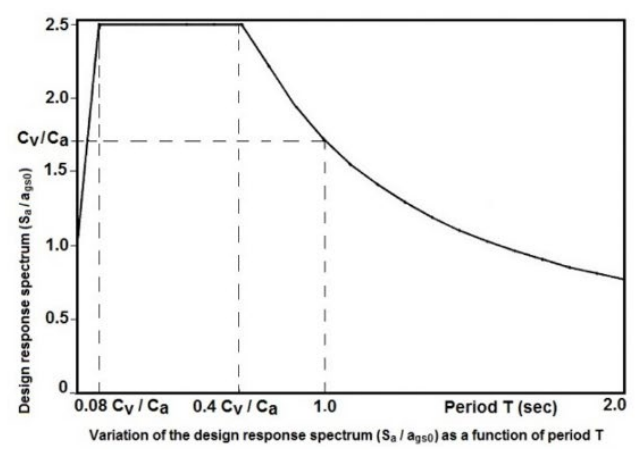

(b)

Figure 4. Characteristic seismic acceleration map and design response spectrum (adapted from ABNT [17]).

\section{THE PSHA METHODOLOGY APPLIED TO THE ANALYSIS OF RN STATE}

The PSHA methodology, didactically divided into four steps according to Table 1, is briefly discussed in sequence. In parallel with it, the analysis of $\mathrm{RN}$ is presented.

Table 1. PSHA steps.

\begin{tabular}{ll}
\hline Step & Description \\
\hline 1 & Identification of the seismic sources from historical, tectonic and geological surveys (Figure 5a) \\
\hline 2 & $\begin{array}{l}\text { Characterization of the seismic sources: maximum and minimum magnitudes determination, and definition of the } \\
\text { seismic recurrence law (Figure } 5 \mathrm{~b} \text { ) }\end{array}$ \\
\hline 3 & $\begin{array}{l}\text { Prediction of the resulting distribution of ground motion intensity as a function of earthquake magnitude, distance, etc., } \\
\text { by ground models (Figure } 5 \mathrm{c} \text { ) }\end{array}$ \\
\hline $\begin{array}{l}\text { Calculation of the exceedance probability and return period for a given ground motion intensity as a combination of } \\
\text { previous information (Figure } 5 \mathrm{~d} \text { ) }\end{array}$ \\
\hline
\end{tabular}
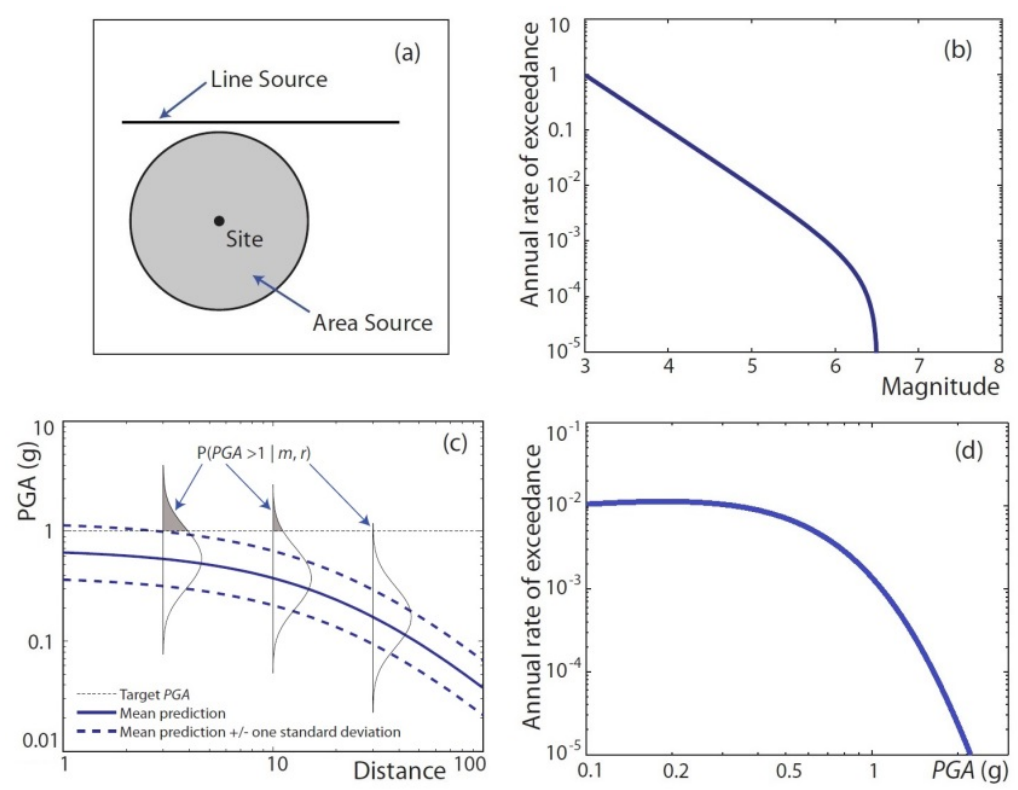

Figure 5. PSHA steps (adapted from Baker [24]). 


\subsection{Seismic source identification}

Seismic sources are sites that have relative uniform seismic characteristics and are distinct from the nearby ones. First, it is necessary to determine all the sources capable of producing some energy that generate soil vibration at the analysis location.

Budnitz et al. [33] indicate that seismic sources can be categorized into four basic types: (a) geological faults, represented as lines or planes (Figure 6a); (b) areas enclosing concentrated zones of seismicity (Figure 6b); (c) regional areas (Figure 6c); and (d) background areas (Figure 6d) with diffuse seismicity (note the scale in Figure 6d).
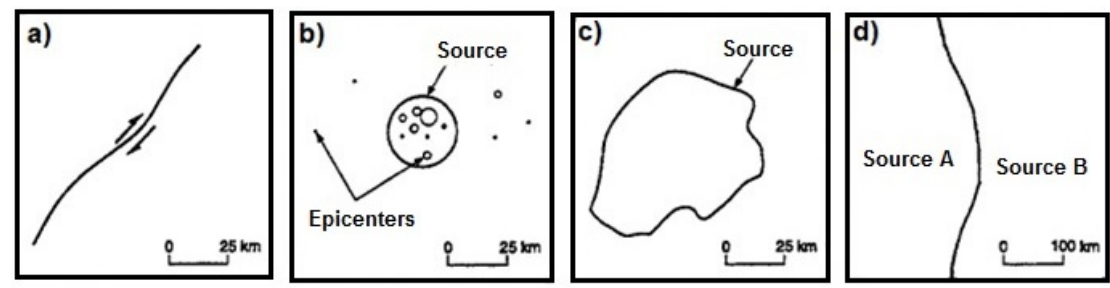

Figure 6. Seismic source types (adapted from Budnitz et al. [33]).

In intraplate regions, the seismic source identification can be complex and, according to Almeida [34], its characterization is extremely dependent on the tectonic environment considered, which makes it a difficult task for regions with low seismicity. This occurs because there is no clear correlation between seismicity and the known tectonic structures or surface geology.

Although in RN the main seismic source is the "Samambaia fault" (presented in section 2), in this study the seismic source was not defined as a line, but as an area with uniform seismicity. This is a simplification, which tends to be suitable for regions with low seismicity, such as RN. It is important to highlight that such procedure do not cause a seismic hazard amplification, since in the characterization of this source (discussed in the next subsection), only the events that actually occurred in the target area are considered.

\subsection{Seismic source characterization}

For the seismic source identification and characterization phases, according to Pirchiner [35], all the available geological knowledge must be considered to define: (a) the spatial geometry of the geological feature and the probable seismic source; and (b) the number of earthquakes related to the energy released by each one (ratio number of events versus magnitude). Budnitz et al. [33] establish three key elements for the source characterization:

(a) Seismic source locations/geometries. The seismic sources are defined in locations within the earth's crust that have relatively uniform seismicity characteristics;

(b) Maximum earthquake magnitude. It is the upper-bound magnitude to the earthquake recurrence (frequencymagnitude) curve. Baker [24, pp. 44] complements this key element, explaining about the minimum earthquake magnitude: "For practical reasons, not all earthquake magnitudes are considered in PSHA calculations. Typically, only earthquakes with magnitudes greater than approximately 4.5 or 5 are considered. This is chosen as a conservative value, for which the omitted small-magnitude earthquakes are not believed to be capable of damaging structures, and thus not relevant for seismic risk calculations. This also reduces the size of the calculations. The exact magnitude at which an earthquake is no longer damaging is not obvious, however, and unfortunately the choice of cutoff magnitude can significantly affect some PSHA results".

(c) Earthquake recurrence. This is the frequency of the several earthquake occurrences (magnitude variable). Recurrence relationships or curves are developed for each seismic source and reflect the frequency of occurrence (usually expressed on an annual basis) of magnitudes up to the maximum. This earthquake recurrence, which is an essential information, is usually associated with a relationship known as Gutenberg-Richter law (Equation 1):

$\log \lambda_{\mathrm{m}}=\mathrm{a}-\mathrm{bm}$

Where:

$\mathrm{m}=$ magnitude value of reference;

$\lambda_{\mathrm{m}}=$ the earthquake rate (or the number of events per year, also represented by $\sum \mathrm{N}$ ) with magnitudes greater than or equal to a minimum "m";

"a" and "b" = coefficients that depend on the characteristics of each location and are determined from statistical analysis of historical observations, obtained through catalogs produced by institutions devoted to earthquake records. 
Related to Brazil, Almeida et al. [25] and Borges et al. [7] adopted the maximum of M7.0 for the continental area, what is commonly used for stable continental regions worldwide, except for very special areas. According to Almeida [34], for locations classified as source areas, the maximum magnitude is determined by earthquake's historical data in the region. Thus, it is common to add half a unit to the maximum historical magnitude to represent the possible maximum one from that source.

It is acceptable that the largest earthquakes in RN may be considered between the values M5.5 and M6, according to what is observed from the seismological and geological data. The absence of events greater than M6 in the past 180 years may indicate a possible recurrence of earthquakes with this magnitude. Therefore, it would be reasonable to adopt M6.5 as maximum, like Dourado [36] did when studied the states of CE and RN. For the minimum magnitude, M4.5 was considered, similar to the value used by Almeida et al. [25] and Borges et al. [7].

Regarding the law of recurrence, it should be emphasized that the precise determination of the parameters for the $\mathrm{RN}$ or a detailed discussion about its methodology are beyond the objectives of this study. Thus, some relationships already defined for the region and available in the literature will be used. Ideally, it should be as up-to-date as possible, in order to reflect numerically the real situation. So, according Equation 1, Marza et al. [37] studied the state of CE, defining the values $\mathrm{a}=2.92$ and $\mathrm{b}=1.01$; Almeida [34] refers to the entire Northeast, using the expression with the values $\mathrm{a}=3.10$ and $\mathrm{b}=0.93$; and Dourado [36] considered $\mathrm{CE}$ and $\mathrm{RN}$, adopting $\mathrm{a}=3.1131 \mathrm{and} \mathrm{b}=0.96$. In short:

$\log \lambda_{\mathrm{m}}=2.92-1.01 \mathrm{~m}$ (Marza's law)

$\log \lambda_{\mathrm{m}}=3.10-0.93 \mathrm{~m}$ (Almeida's law)

$\log \lambda_{\mathrm{m}}=3.1131-0.96 \mathrm{~m}$ (Dourado's law)

However, as these laws cover a larger area than the considered in this study, it is necessary to correct the parameter "a" of the Equation 1 to "al", according to the Equation 5. The logic is to maintain the "seismic density" as constant.

$a_{1}=a-\log _{10}\left(\frac{A_{0}}{A_{1}}\right)$

Where:

$\mathrm{A}_{0}=$ original area related to the recurrence law (Marza's or Almeida's or Dourado's law);

$\mathrm{A}_{1}=$ new area related to the present study (illustrated in section 5.1, in sequence);

Finally, the recurrence laws become (the expressions below were used in analysis):

$\log \lambda_{\mathrm{m}}=2.356-1.01 \mathrm{~m}$ (modified Marza's law)

$\log \lambda_{\mathrm{m}}=1.785-0.93 \mathrm{~m}$ (modified Almeida's law)

$\log \lambda_{\mathrm{m}}=2.267-0.96 \mathrm{~m}$ (modified Dourado's law)

Although the three equations are numerically similar, the seismic hazard calculation is very sensitive to these coefficients and any variation causes significant changes in the results, especially due to the influence of the higher magnitudes. The ideal procedure, obviously, is to deduce a specific recurrence law for the state of RN.

\subsection{Prediction of the resulting distribution of ground motion intensity}

Now it is important to define models, which adequately describe the seismic ground movement from earthquake epicenter to the desired location, considering its magnitude, distance, attenuation, and other parameters. These models 
are named as Ground Motion Prediction Equations (GMPE) or Ground Motion Prediction Models (GMPM). Douglas [38] presents an extensive collection with 452 GMPE developed and studied between 1964 and 2018 around the world.

Usually, the acceleration is considered as the ground motion parameter, assuming that it is a random variable, with dispersion around the mean (standard deviation). The graph shown in Figure 5c illustrates a central continuous trace that represents the mean values of PGA, given by a GMPE, for which a magnitude value is set. It is observed that this curve has a decreasing trend, that is, the greater the distance from the earthquake, the smaller the accelerations caused by the event.

Unfortunately, there is no study defining a specific GMPE for any region of Brazil. In such cases, McGuire [23] suggests the use of a GMPE from similar sites. Bommer et al. [39] affirm that it is not necessary to choose a mathematical model from the same analyzed area, and it is possible to adopt models of places with similar seismic conditions, even though these have been developed in very distant regions.

In fact, there is a specific GMPE for RN (Dantas [40]), but limited to magnitudes lower than M3.0, which is not feasible for a seismic hazard analysis. Truly, this model is a simplification of Toro et al. [41] GMPE, originally formulated for the Central and the Eastern area of the USA, which has been widely used by Brazilian researches for its geological similarities (e.g. Borges et al. [7]; Almeida et al. [25]; Santos et al. [26]; and Dourado [36]).

Toro et al. [41], Atkinson and Boore [42], and Atkinson [43] GMPE were used in this study. The last two models were related to the Eastern USA, applicable to a stable continental type tectonic region. From this point on, the GMPE will be referred as "Toro", "Atk. \& Boore", and "Atkinson". It is important to highlight that all these GMPE were set to hard rock soil type (NBR 15421, Class "A").

\subsection{Calculation of the exceedance probability and the return period}

The PSHA's main result is the acceleration hazard curve, obtained by repeating the calculation for many different levels of acceleration. The curve shows the relation between this parameter and its exceedance probability, or its annual rate of exceedance $(\lambda)$, as can be seen by a single example in Figure 7 . In other words, this curve represents the probabilities of the acceleration values being exceeded, and this probability decreases as its level increases.

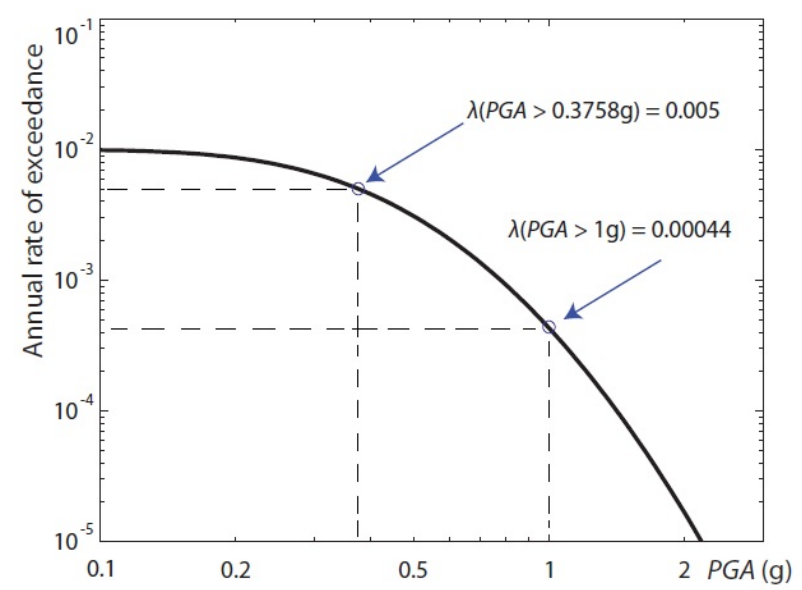

Figure 7. Example of a PGA hazard curve (adapted from Baker [24]).

Some important observations about the PGA hazard curve:

(a) Usually, one or both axes of the graph are plotted in log scale because they often cover several orders of magnitude, and the vertical-axis contains very small values;

(b) On the horizontal-axis, there are the values of the spectral acceleration (accelerations associated with any period, or frequency) resulting from spectral analysis. Figure 7 also indicates the PGA, when the period is equal to zero;

(c) the curve is drawn for a specific point in the studied area, while a seismic hazard map is valid for a certain region, that is, several points (in this case, the probability is fixed);

(d) The variable called "return period" (T) is very important and is defined as the inverse of the "annual rate of occurrence". For example, if a given ground motion has a 0.02 annual rate of occurrence, then the return period is 
equal to $1 / 0.02=50$ years. However, as this does not imply that the ground motion will be exceeded exactly once every 50 years, the term is more precisely defined as the "mean return period" because 50 years is the average time between exceedances.

(e) For a given "probability of exceedance" (PE), it is possible to compute the "occurrence rate of events" $(\gamma)$ related to a given ground motion, associated to "t" years of exposure. The inverse calculation is obviously possible. As the ground motion occurrences follow a Poisson distribution, by hypothesis, Equations 9 and 10 express:

$\gamma=-[\ln (1-\mathrm{PE})] / \mathrm{t}$

$\mathrm{PE}=1-\mathrm{e}^{-\gamma \mathrm{t}}$

For example, if a given ground motion has a probability of exceedance $\mathrm{PE}=10 \%=0.10$, considering a period of time $\mathrm{t}=50$ years, the occurrence rate $\gamma=0.0021072$ per year, which is associated to one event each 475 years $(475=1$ / 0.0021072). This value corresponds to the "mean return period" $(\mathrm{T})$.

Equation 10 can also be formulated considering $\mathrm{T}$ directly, resulting in:

$\mathrm{PE}=1-\left(1-\frac{1}{\mathrm{~T}}\right)^{\mathrm{t}}$

For example, if a given ground motion has a probability of exceedance $\mathrm{PE}=2 \%=0.02$, considering a period of time $\mathrm{t}=50$ years, the mean return period $\mathrm{T}=2475$ years. The same may be applied to obtain different return periods, indicated in section 3 for some codes.

\section{RESULTS AND COMMENTS}

\subsection{Introduction}

The purpose of the analyses is to evaluate if the design criteria presented by NBR 15421 are consistent with the RN reality, whether in terms of the maximum acceleration values, or in the form and values of the design response spectrum. All simulations considered the mean return period of 475 years (like NBR 15421).

The proper software should perform calculation based on probabilities (not a deterministic process) and in this study the R-CRISIS v20.1 was the chosen one. Dourado [36] and Borges et al. [7] also used it, although in previous versions. Details on the capacity and evolution of the software were presented by Aguilar-Meléndez et al. [44].

R-CRISIS software provides the seismic acceleration map for the studied area with a color gradient. In Figure 8, there is an example for RN. The acceleration value is constant and equal to the maximum at the center of the seismic source area (red plots), decreasing in the points far from it. The PGA expressed in the results is the acceleration maximum value. The quadrilateral area in Figure 8 is the new area related to the present study and to the Equation 5 . 


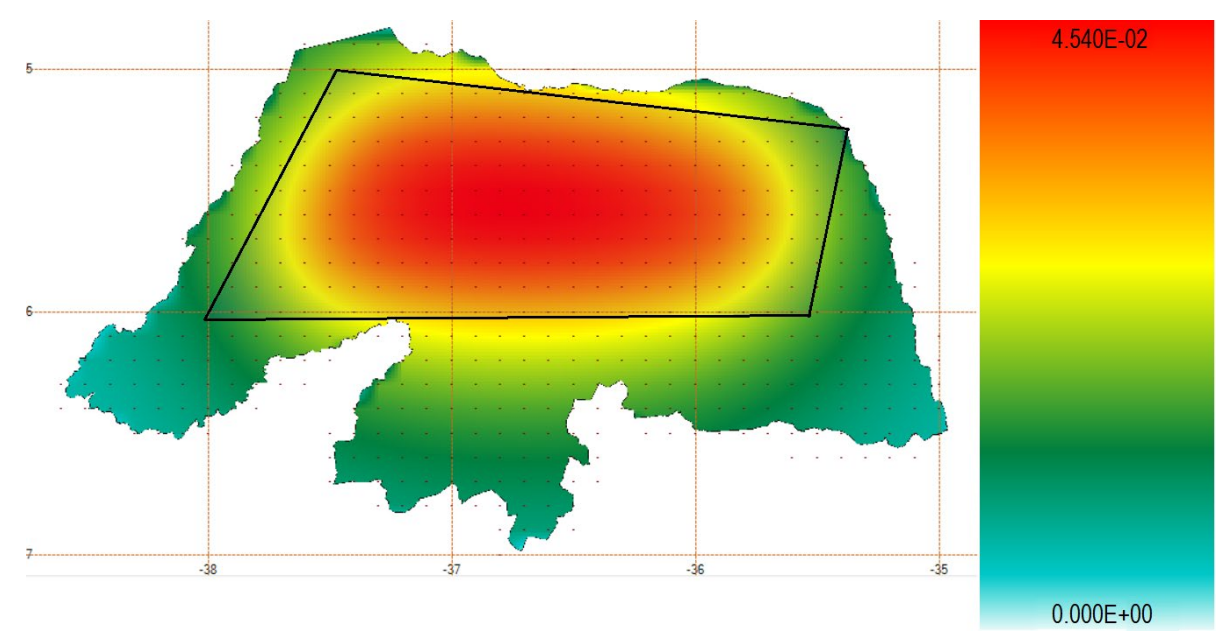

Figure 8. Example of a hazard map for RN obtained from R-CRISIS 20.1.

At last, it should be highlighted that, usually in order to reduce the uncertainties in the hazard analysis, it is common to adopt a logic tree, what it was not considered in this paper. Logic tree is an approach to capture and to quantify the uncertainties associated with the parameters required to perform the analysis (Bommer et al. [45]), as those mentioned in section 3. So, the practice is the use of multiple input options considering different seismic zone models, seismic activity parameters, scale factors, among others.

\subsection{Analysis varying the recurrence laws}

Initially, the modified recurrence laws (section 4.2) were evaluated by adopting, separately, each one of the three GMPE (section 4.3). The results are shown in Table 2 and Figure 9. In this figure, and others, the design response spectrum of NBR 15421 will always be plotted together with the result curves to better illustrate the differences between it and the numerical simulations. The X-axis is the natural period (s) and the Y-axis is the acceleration (fraction of "g").

It can be observed that all the curves are beneath the code spectrum, for the three GMPE. Dourado's law always is related to the highest values and Atkinson is the most conservative GMPE. About the PGA, Table 2 shows that the NBR 15421 value (reference) is superior to the results of the numerical simulations, except for Atkinson in two situations.

Note that the characteristic horizontal acceleration value for $\mathrm{RN}$ is $0.05 \mathrm{~g}$, illustrated in Figure 3a, considering a rock type soil (Class B). Because the GMPE used in this paper were formulated for a hard rock type soil (Class A), it is necessary to convert the acceleration basis for Class A. The NBR 15421 conversion coefficient is 0.8 . So, this value corresponds a $0.04 \mathrm{~g}(4 \% \mathrm{~g})$ and all the results exposed in sequence are referenced to a hard rock type soil (Class A).

Table 2. PGA value (\% g) considering different recurrence laws.

\begin{tabular}{lllll}
\hline GMPE & Almeida's law & Dourado's law & Marza's law & NBR 15421 [17] \\
\hline Toro & $1.00 \%$ & $2.77 \%$ & $1.84 \%$ & $4.00 \%$ \\
\hline Atkinson & $2.86 \%$ & $6.00 \%$ & $4.54 \%$ & $4.00 \%$ \\
\hline Atk \& Boore & $0.50 \%$ & $1.36 \%$ & $0.90 \%$ & $4.00 \%$ \\
\hline
\end{tabular}



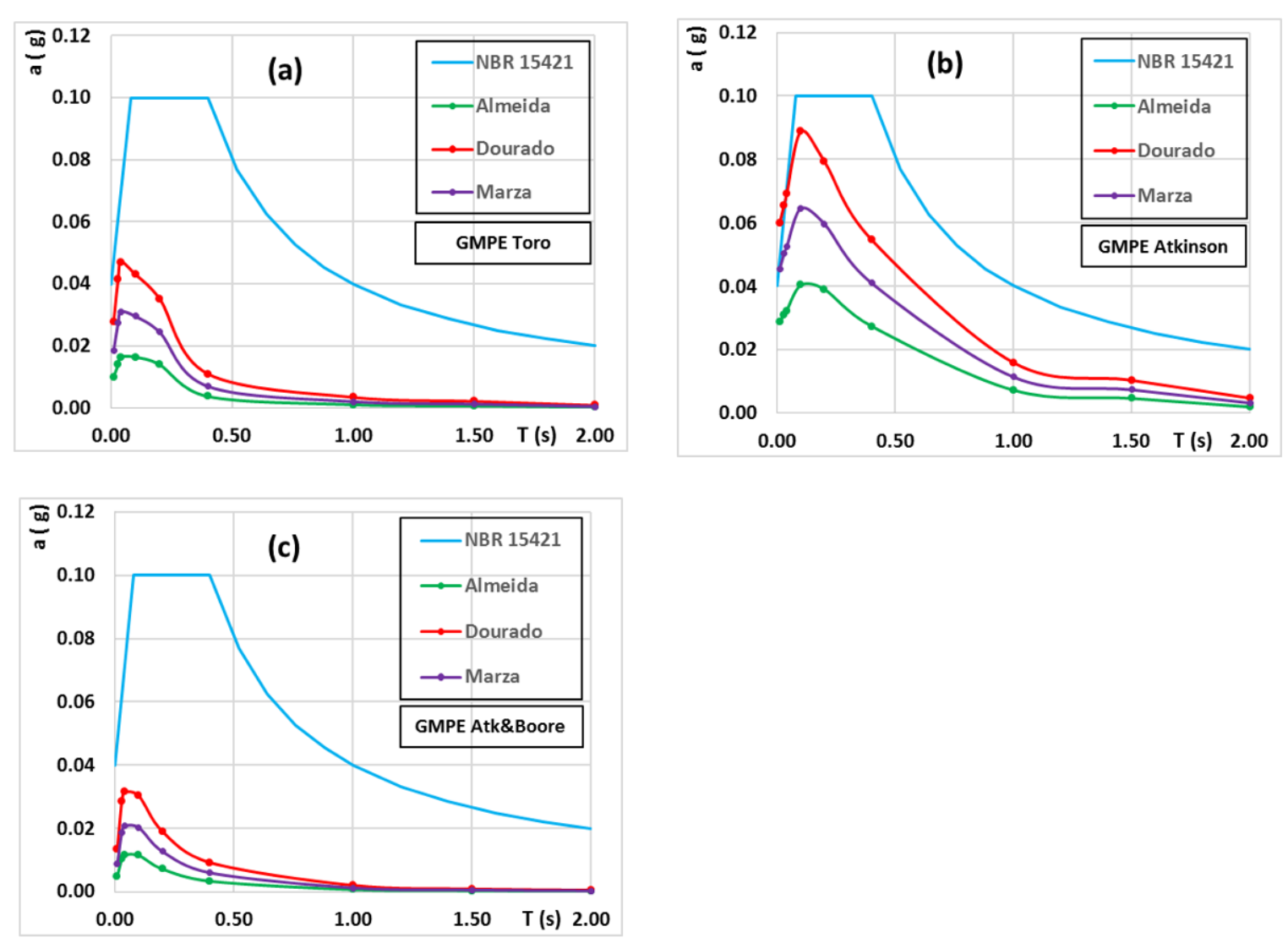

Figure 9. Response spectra for different recurrence laws.

\subsection{Analysis varying the GMPE}

It can be seen from Figure 9 that Dourado's law is the most conservative one and as it is the most recent publication, it will be taken as reference in the next analyses. Figure 10 illustrates, for better visualization, the three GMPE curves together using the modified Dourado's law. As already seen in Figure 9, the Atkinson model is the closest to the NBR 15421 design response spectrum (but still lower, except for the PGA value).

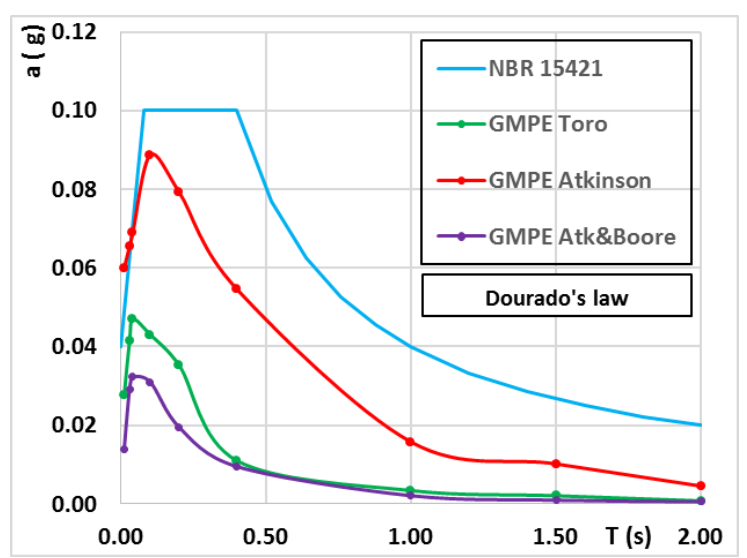

Figure 10. Response spectra for different GMPE. 


\subsection{Analysis varying the mean return period}

One of the most important definitions in the PSHA is the mean return period, as discussed in section 3. Several codes, as NBR 15421, consider 475 years (PGA with PE $=10 \%$ in 50 years). Other codes, however, have increased the rigor of the criterion, changing this value to 2475 years (PGA with $\mathrm{PE}=2 \%$ in 50 years). McGuire [23] notes that the period of time $t=50$ years is associated to the usual nominal lifetime of major civil structures, and the difference between the two criteria, of course, is only the probability of exceedance. This discussion has not yet been carried out in Brazil.

So, Table 3 and Figure 11 aims to make a simple comparison and encourage discussion about the engineering judgment of changing this mean return period. Figure 11 shows the response spectra for Dourado's law and the three GMPE. Table 3 shows that the PGA values for a return period of 2475 years are the double or triple the NBR 15421 PGA (return period of 475 years), for any GMPE. The difference is significant, but this comparison cannot be made directly because the mean return periods are not the same.

Table 3. PGA value ( $\% \mathrm{~g})$ considering different mean return periods.

\begin{tabular}{lllll}
\hline Main return period & Toro & Atkinson & Atk and Boore & NBR 15421 [17] \\
\hline 475 years & $2.77 \%$ & $6.00 \%$ & $1.36 \%$ & $4.00 \%$ \\
\hline 2475 years & $11.00 \%$ & $12.60 \%$ & $7.11 \%$ & - \\
\hline
\end{tabular}
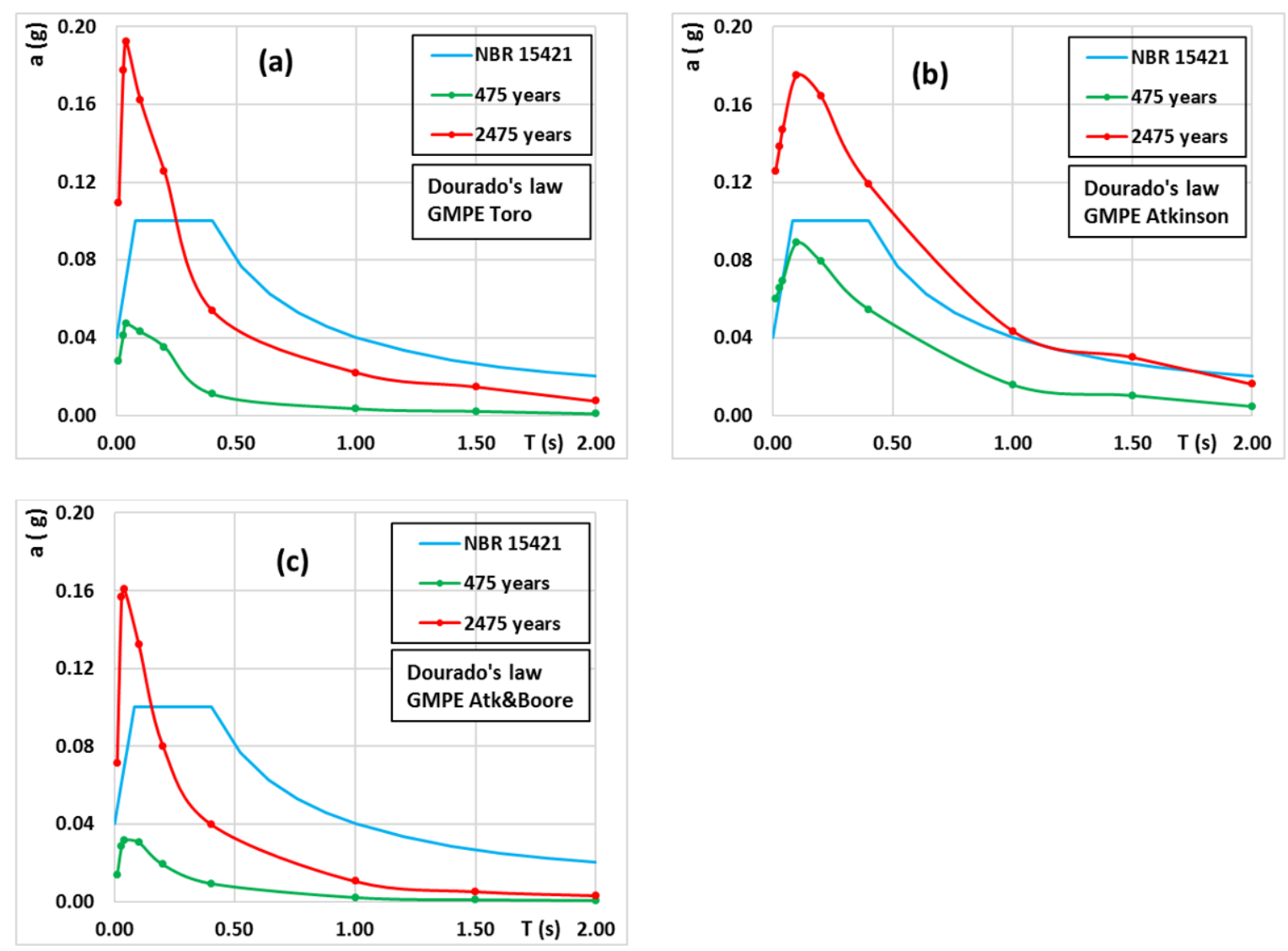

Figure 11. Response spectra for different mean return periods. 


\subsection{Design response spectrum shape}

It should be highlighted that the shape of the response spectra derived from the analyses differs from the design spectrum presented in the NBR 15421 code. They present a higher peak and decrease with a higher ratio (the constant horizontal line is almost nonexistent).

FIB [46, pp. 91] describes that the author Free, in 1996,

[...] observed that ground motions from intraplate earthquakes have response spectral amplitudes that are appreciably higher than those from interplate earthquakes for high frequencies (greater than $10 \mathrm{~Hz}$ ); although for lower frequencies the amplitude are similar.

Frequencies greater than $10 \mathrm{~Hz}$ is equivalent to periods lower than $0.1 \mathrm{~s}$, and lower frequencies mean higher periods. This seems to be exactly what is illustrated in the previous figures.

FIB [46, pp. 91] still alerts that "[...] there is very significant scatter in the attenuation relationships and there are also important differences from one stable continental region to another [...]". For last, this reference notes that the differences between strong-motion characteristics in intraplate and interplate regions are usually attributed to source and path effects. In terms of the path effects, inelastic attenuation is generally assumed to be greater in the more fragmented interplane regions. Despite these observations, a more accurate study should be conducted in order to analyze if the Brazilian standard design response spectrum should be improved considering different spectra curves (shapes) according the building site.

\section{CONCLUSIONS}

Brazil is not free of earthquakes, despite an evident relatively low seismic activity, in general. The correct technique must be used in order to assess the seismic hazard level in areas where the engineering judgment considers necessary, and the probabilistic seismic hazard analysis (PSHA) is an adequate methodology for this objective.

This paper presents analyses considering PSHA approach towards improving the hazard map, the peak ground acceleration value and the response spectrum of the state of Rio Grande do Norte, one of the most seismically active areas in Brazil, considering different recurrence laws and different ground motion prediction equations.

It was verified that the peak ground acceleration values and the response spectra obtained from the analyses are usually lower when compared to the design criteria defined by the Brazilian code NBR 15421. So, the code establishes conservative and adequate parameters.

A next stage of this work should be the adoption of a logic tree approach, in order to reduce the uncertainties in the hazard calculations. A second discussion, which might be faced, is the modification of the design mean return period, like what has already been done in other international codes. Evidently, this change will lead to more conservative results and should be developed based on specific studies.

\section{ACKNOWLEDGEMENTS}

The authors are grateful to Prof. Marcelo S. de Assumpção (IAG/USP) for providing the updated Brazilian seismic maps and to Prof. Sergio Hampshire de C. Santos (UFRJ) for clarifying some aspects of the methodology.

\section{REFERENCES}

[1] P. Talwani Introduction. in Intraplate Earthquakes, P. Talwani, Ed., Cambridge, U.K.: Cambridge University Press, 2014 , pp. 1-7. http://doi.org/10.1017/CBO9781139628921.002.

[2] J. Berrocal et al., Sismicidade do Brasil. São Paulo: IAG-USP/CNEN, 1984.

[3] M. B. Bianchi et al., "The Brazilian seismographic network (RSBR): improving seismic monitoring in Brazil," Seismol. Res. Lett., vol. 89, no. 2A, pp. 452-457, 2018, http://dx.doi.org/10.1785/0220170227.

[4] A. E. V. Lopes, and L. C. Nunes. "Intensidades sísmicas de terremotos: formulação de cenários sísmicos no Brasil," Rev USP, no. 91, pp. 90-103, Nov. 2011, https://doi.org/10.11606/issn.2316-9036.v0i91p90-103.

[5] M. Assumpção et al. "Intraplate seismicity in Brazil," in Intraplate Earthquakes, P. Talwani, Ed., Cambridge, U.K.: Cambridge University Press, 2014, pp. 50-71. https://doi.org/10.1017/CBO9781139628921.004

[6] M. S. Assumpção, "Terremotos e a convivência com as incertezas da natureza," Rev USP, no. 91, pp. 76-89, Nov. 2011. https://doi.org/10.11606/issn.2316-9036.v0i91p76-89. 
[7] R. G. Borges, M. S. Assumpção et al. "Seismicity and seismic hazard in the continental margin of southeastern Brazil," J. Seismol., vol. 24, pp. 1205-1224, 2020, http://dx.doi.org/10.1007/s10950-020-09941-4.

[8] P. Talwani, Ed., Intraplate Earthquakes. Cambridge, U.K.: Cambridge University Press, 2014. https://doi.org/10.1017/CBO9781139628921.

[9] H. Agurto-Detzel et al., "Intraplate seismicity in mid-plate South America: correlations with geophysical lithospheric parameters," in Seismicity, Fault Rupture and Earthquake Hazards in Slowly Deforming Regions, A. Landgraf et al., London, U.K.: Geological Society, 2017. Special Publications. https://doi.org/10.1144/SP432.5.

[10] A. Saadi, "Neotectônica da plataforma brasileira: esboço e interpretação preliminares," Rev. Geonomos, vol. 1, no. 1, pp. 1-15, Feb 1993, http://dx.doi.org/10.18285/geonomos.v1i1e2.233.

[11] A. Saadi et al., Map and Database of Quaternary Faults and Lineaments in Brazil. USA: USGS, 2003. U. S. Geological Survey Open-File Report 02-230. https://doi.org/10.3133/ofr02230.

[12] S. E. Hough Intraplate seismic hazard: Evidence for distributed strain and implications for seismic hazard. in Intraplate Earthquakes, P. Talwani (Ed.), Cambridge: Cambridge University Press, 2014, pp. 303-327. https://doi.org/10.1017/CBO9781139628921.013.

[13] K. Pitilakis et al., Systemic Seismic Vulnerability and Risk Analysis for Buildings, Lifeline Networks and Infrastructures Safety Gain. Luxembourg: Publications Office of the European Union, 2013. https://doi.org/10.2788/23242.

[14] Federal Emergency Management Agency, FEMA P-58-1 - Seismic Performance Assessment of Buildings, vol. 1, Methodology, 2nd ed. Washington, D.C.: FEMA, 2018. Accessed: Jul 18, 2020. [Online]. Available: https://www.fema.gov/medialibrary/assets/documents/90380

[15] M. M. Kassem, F. M. Nazri, and E. N. Farsangi, "The seismic vulnerability assessment methodologies: A state-of-the-art review," Ain Shams Eng. J., vol. 11, no. 4, pp. 849-864, 2020. https://doi.org/10.1016/j.asej.2020.04.001.

[16] P. Paultre et al., "Damage to engineered structures during the 12 January 2010, Haiti (Léogâne) earthquake," Can. J. Civ. Eng., vol. 40, no. 8, pp. 777-790, 2013, http://dx.doi.org/10.1139/cjce-2012-0247.

[17] Associação Brasileira de Normas Técnicas. Projeto de Estruturas Resistentes a Sismos - Procedimento, NBR 15241:2006, 2006.

[18] J. M. Ferreira et al., "Superposition of local and regional stresses in northeast Brazil: evidence from focal mechanisms around the Potiguar marginal basin," Geophys. J. Int., vol. 134, no. 2, pp. 341-355, Aug 1998., http://dx.doi.org/10.1046/j.1365246x.1998.00563.x.

[19] F. H. R. Bezerra et al., "Review of active faults in the Borborema Province, Intraplate South America - Integration of seismological and paleoseismological data," Tectonophysics, vol. 510, no. 3-4, pp. 269-290, Oct 2011, http://dx.doi.org/10.1016/j.tecto.2011.08.005.

[20] Á. F. C. Reis et al., "Stress magnitude and orientation in the Potiguar Basin, Brazil: Implications on faulting style and reactivation," $J$. Geophys. Res. Solid Earth, vol. 118, pp. 5550-5563, 2013., http://dx.doi.org/10.1002/2012JB009953.

[21] F. H. R. Bezerra et al., "Coseismic reactivation of the Samambaia fault, Brazil," Tectonophysics, vol. 430, no. 1-4, pp. 27-39, Feb 2007, http://dx.doi.org/10.1016/j.tecto.2006.10.007.

[22] L. Reiter, Earthquake Hazard Analysis: Issues and Insights. New York: Columbia University Press, 1990.

[23] R. K. McGuire, Seismic Hazard and Risk Analysis. EEEI, 2004.

[24] J. W. Baker, Introduction to Probabilistic Seismic Hazard Analysis, 2013. White Paper Version.

[25] A. A. D. Almeida et al., "Probabilistic seismic hazard analysis for a nuclear power plant site in southeast Brazil," J. Seismol., vol. 23, pp. 1-23, 2018, http://dx.doi.org/10.1007/s10950-018-9755-8.

[26] S. H. C. Santos, S. S. Lima, and F. C. M. Silva, Seismic Hazard for Brazilian Northeastern Region. IBRACON Struct. Mater. J., vol. 3, n. 3, p. 374-389, Sep. 2010. Accessed: Jul 18, 2020. [Online]. Available: http://www.ibracon.org.br/publicacoes/revistas_ibracon/riem/volume3_n3.asp

[27] M. D. Petersen et al., "Seismic hazard, risk, and design for south america," Bull. Seismol. Soc. Am., vol. 108, no. 2, pp. 781-800, Jan 2018, http://dx.doi.org/10.1785/0120170002.

[28] American Society of Civil Engineers, Seismic Evaluation and Retrofit of Existing Buildings, ASCE/SEI 41-17. 2017. https://doi.org/10.1061/9780784414859.

[29] Comité Européen De Normalisation, Eurocode 8: Design of structures for earthquake resistance - Part 1: General rules, seismic actions and rules for buildings, EN 1998-1:2004:E, 1998.

[30] American Society of Civil Engineers, Minimum Design Loads and Associated Criteria for Buildings and Other Structures, ASCE/SEI 7-16, 2016. https://doi.org/10.1061/9780784414248.

[31] P. G. B. Nóbrega et al., "Sobre os mapas de perigo sísmico para o projeto de estruturas," in Cong. Brasileiro do Concreto, Vol. 61, Fortaleza, 2019. Available: https://www.researchgate.net/publication/336672092

[32] S. H. C. Santos and S. S. Lima, Base sismológica para a a zonificação sísmica da ABNT NBR 15421. Concr. Constr., vol. 92, p. 7277, Out-Dez. 2018. Accessed: Jul 18, 2020. [Online]. Available: http://ibracon.org.br/Site_revista/Concreto_Construcoes/pdfs/revista92.pdf 
[33] R. J. Budnitz et al., Recommendations for Probabilistic Seismic Hazard Analysis: Guidance on Uncertainty and Use for Experts. Vol. 1. Livermore: Lawrence Livermore National Laboratory, 1997. NUREG/CR-6372. Accessed: Jul 18, 2020. [Online]. Available: https://www.nrc.gov/reading-rm/doc-collections/nuregs/contract/cr6372/vol1/index.html

[34] A. A. D. Almeida, "Análise Probabilística de Segurança Sísmica de Sistemas e Componentes Estruturais," PhD thesis, Univ. Fed. Rio Jan., Rio de Janeiro, 2002. https://doi.org/10.17771/PUCRio.acad.2667.

[35]M. Pirchiner, "Técnicas de suavização aplicadas à caracterização de fontes sísmicas e à análise probabilística de ameaça sísmica," MSc thesis, Esc. Matem. Apl., Fund. Get. Vargas, Rio de Janeiro, 2014. [Online]. Available: http://hdl.handle.net/10438/14010

[36]J. C. Dourado, "Mapa de ameaça sísmica do Brasil," in Anais Cong. Bras. Geol., Vol. 47, Salvador, 2014.

[37] V. I. Marza, et al., Breve Caracterização da Sismicidade no Ceará. Brasília: Observatório Sismológico, Universidade de Brasília, [20--?].

[38] J. Douglas Ground Motion Prediction Equations 1964-2018. Glasgow: Department of Civil and Environmental Engineering, University of Strathclyde, 2019. Accessed: Jul 18, 2020. [Online]. Available: http:/www.gmpe.org.uk/gmpereport2014.pdf

[39] J. J. Bommer et al., "On the selection of ground-motion prediction equations for seismic hazard analysis," Seismol. Res. Lett., vol. 81, no. 5, pp. 783-793, Aug 2010, http://dx.doi.org/10.1785/gssrl.81.5.783.

[40]R. R. S. Dantas, "Decaimento da aceleração de ondas sísmicas dos terremotos na borda da Bacia Potiguar," Bacharel, Univ. Fed. Rio Gde Norte, Natal, 2012.

[41] G. R. Toro, N. A. Abrahamson, and J. F. Schneider, "Model of strong ground motions from earthquakes in central and eastern north america: best estimates and uncertainties," Seismol. Res. Lett., vol. 68, no. 1, pp. 41-57, Jan 1997, http://dx.doi.org/10.1785/gssrl.68.1.41.

[42] G. M. Atkinson and D. M. Boore, "Earthquake ground-motion prediction equations for eastern north america," Bull. Seismol. Soc. Am., vol. 96, no. 6, pp. 1304-1318, Jun 2008, http://dx.doi.org/10.1785/0120050245.

[43] G. M. Atkinson, "Ground-motion prediction equations for eastern north america from a referenced empirical approach: implications for epistemic uncertainty," Bull. Seismol. Soc. Am., vol. 96, no. 3, pp. 2181-2205, Dec 2006, http://dx.doi.org/10.1785/0120070199.

[44] A. Aguilar-Meléndez et al., "Development and validation of software CRISIS to perform probabilistic seismic hazard assessment with emphasis on the recent CRISIS2015," Comput. Sist., vol. 21, no. 1, pp. 67-90, 2017, http://dx.doi.org/10.13053/cys-21-1-2578.

[45] J. J. Bommer et al., "On the use of logic trees for ground-motion prediction equations in seismic-hazard analysis," Bull. Seismol. Soc. Am., vol. 95, no. 2, pp. 377-389, 2005, http://dx.doi.org/10.1785/0120040073.

[46] Fédération Internationale Du Béton, "Displacement-based seismic design of reinforced concrete buildings," fib CEB- FIP, no. 25, 2003, http://dx.doi.org/10.35789/fib.BULL.0025.

Authors contributions: PGBN: conceptualization, methodology, analysis, writing - original draft, supervision; BRSS: investigation, formal analysis, writing - review; SHSN: writing - review and editing, supervision.

Editors: Sergio Hampshire C. Santos, Guilherme Aris Parsekian. 